\title{
Reference framework for active learning in higher education
}

\author{
Pranav Naithani \\ BIT International Center, Kingdom of Bahrain (pranavnaithani@gmail.com)
}

Cite as: Naithani, P. (2008). Reference framework for active learning in higher education. In AlHawaj, Elali and Twizell (Eds.) Higher Education in the Twenty-First Century: Issues and Challenges, 113-120, Taylor \& Francis Group, London.

\begin{abstract}
The work presented in this paper traces the history of active learning and further utilizes the available literature to define meaning and importance of active learning in higher education. The study highlights common practical problems faced by students and instructors in implementing active learning in higher education and further identifies a set of individual practices being used worldwide to overcome the obstacles. Expectations and responsibilities of students and instructors are also specified to enhance the efficiency of active learning environment. The paper also traces the importance of student and instructor rapport for a successful learning environment.
\end{abstract}

Keywords: Active learning, higher education, problem based learning.

\section{Introduction}

Can a person expect to get a car driving license just by attending the theoretical classes? Let us hypothetically assume the person manages to get a license, but will he be able to drive the car? No. To be a perfect car driver a person has to and does take real life driving classes. He develops new skills by actually driving along with the trainer.

Higher education aims at an optimal blend of knowledge and skills. It provides a license to the student for driving successfully through the maze of what, when, why, who and how. Usually the next step after higher education is a professional career. This is why role and importance of active learning, and not passive learning (in which an instructor depends solely or predominantly on passive lectures), is crucial throughout higher education.

\section{Active learning}

Roots of active learning can be traced to Confucius (551-479 BC), who stated, "I hear and I forget. I see and I remember. I do and I understand". Socrates (470-399 BC) had similar views when he said that "I cannot teach anybody anything. I can only make them think".

Dale (1969) established following relationships between level of involvement of learner and how much the learner remembers:- "We remember: 10\% of what we read, 20\% of what we hear, 30\% of what we see, $50 \%$ of what we hear and see, $70 \%$ of what we say $90 \%$ of what we do". 
Studies show that classroom attention-span of students varies from 15 to 25 minutes (Bligh, 1972 as cited by Cashin, 1985). Meyers \& Jones (1993) found that students' classroom attention is poor for $40 \%$ of the time and they retain $70 \%$ of the information during the first ten minutes and only $20 \%$ of the information during the last ten minutes of a lecture. In a 1997 national survey in USA, of more than 250,000 freshmen at nearly 500 universities, $35.6 \%$ of the students said that they were frequently bored in class. (Berk, 2003)

All these facts stress on the need of active learning environment in particular when, feedback from students has shown that passive lecture in higher education is not a preferred method of learning. (Sander et al., 2000 as cited by Huxman, 2005)

\subsection{Active Learning: Defined}

Literature review highlighted the following characteristics of active learning.

- Learning is enhanced by involving the student in activities and relationships, inside and outside the classroom. (Astin, 1984)

- "Lectures are not well suited to higher levels of learning: application, analysis, synthesis, influencing attitudes or values. Lecturing is best suited to the lower levels of knowledge and understanding." (Cashin, 1985)

- "Learning is not a spectator sport. Students do not learn much just by sitting in classes listening to teachers, memorizing pre-packaged assignments, and spitting out answers. They must talk about what they are learning, write about it, relate it to past experiences and apply it to their daily lives." (Chickering \& Gamson, 1987)

- Higher-order thinking through analysis, synthesis and evaluation is more important than reading, writing and discussing. (Bonwell \& Eison, 1991)

- $\quad$ "Active learning involves providing opportunities for students to meaningfully talk and listen, write, read, and reflect on the content, ideas, issues and concerns of an academic subject." (Meyers \& Jones, 1993)

- "Although humans appreciate the common and the familiar, and often resist change, the brain seeks and reacts to innovative occurrences." (Angelo, 1991 as cited by Forrest, 2004)

- "In fact, rote learning (e.g., memorizing terminology) is frustrating because the brain resists meaningless stimuli." (Forrest, 2004)

Thus we may derive following definition:-

Active learning involves designing, implementing, maintaining and promoting, within and outside classroom, environment for learning, through creating opportunities for active engagement with the subject matter. It strives for higher-order thinking and in-depth comprehension of the learner. 


\subsection{Active Learning: Drawbacks}

Active involvement and interaction of the students translate into loss of teaching time as substantial classroom time is spent on multiple questioning and feedback sessions, (Lammers \& Murphy, 2002 as cited by Huxman, 2005) especially while handling large classes.(Bonwell, C. \& J. Eison, 1991) It results into lesser content coverage in the classroom. (Murray \& Brightman, 1996 as cited by Huxman, 2005). But the biggest roadblock is a creation of the instructor himself and that is fear of failure, fear of loss of control due to enhanced classroom discussions, fear of lack of student participation, and fear of criticism of a new method. (Bonwell, C. \& J. Eison, 1991)

\subsubsection{Handling drawbacks: Short Lectures}

An analysis of research papers on higher education by Chilcoat (1989) found that, continuous rapid lecturing happens at a rate of 120 to 240 words per minute but most of the students can write down only 20 words per minute. Result is half cooked notes and poor understanding during lecture time.

A solution to the above problem can be found in a study conducted by Ruhl et al. (1987), in which the instructor paused for two minutes for three times during a lecture, and during these pauses students worked in pairs to re-discuss the topic discussed by the instructor and then reworked on their class notes to fill up the gaps left while taking down the notes during lecture. During the pauses students did not engage in discussion with the instructor. At the end of the lecture three minutes were given to let the students write down their free recall. Results proved that short lectures of 12 to 18 minutes followed by pauses for student interaction enhance students' learning.

Bonwell and Eison (1991), suggest to conduct guided lecture in which instructor lectures continuously for 20 to 30 minutes without the students taking notes and then allots five minutes for free recall writing by the students followed by small groups of students discussing and analyzing the topic.

\subsubsection{Handling drawbacks: Revised lecture information density}

Russell et al. (1984) conducted a research on 123 medical students and divided them into three groups with no significant difference in cumulative GPA's. First group was exposed to high density lecture with $90 \%$ new content, second group was exposed to medium density lecture with $70 \%$ new content and third to low density lecture with 50\% new content. In each lecture the remaining time was spent on reinforcing the core ideas by actively involving the students and by relating the content to prior experience. Tests after the lectures confirmed that learning and retention was higher with low density content.

Fedler \& Brent (1996) suggest to discuss only core, critical and difficult topics in class, to give brief writing assignments to the students on the self covered topics and then to test the students on 
those topics. Wilke (2003) conducted a research on 141 students in human physiology and found that active learning improved students' content achievement even when the content is reduced. Research had proved time and again that reduced lecture time and reduced lecture information density enhances learning.

\subsubsection{Handling drawbacks: Expectations and responsibilities}

Lesser lecture time in the classroom and lower density content should not lead to lower expectations of the students or instructor. Chickering \& Gamson (1987) suggest "expect more and you will get more". Seeler et al. (1994) suggests that active learning environment does not mean structure less learning environment and it does not mean undermining the importance of theory. Active learning environment not only increases the opportunities for interaction and involvement but also responsibilities. Following are some important expectations and responsibilities as suggested by Seeler et al. (1994).

Students must be more aware and be ready to be responsible for their own professional development. They must increase their level of involvement in the active learning environment and focus on application of theory to real life practice. But this does not mean that the instructor is less responsible for active learning environment. Seeler et al. (1994) further suggest active learning depends on the success of the instructor in helping the students successfully manage transition from passive style of learning to the new one. Instructor needs to understand ability of the student, develop new skills, be aware of practical applications of theory to design exercises and assignments accordingly, adopt the role of facilitator and mentor. Instructor must rely on feedback and make changes, if necessary.

Stinson \& Milter (1996) also highlight instructor's skill development and student transition as two major pillars of active learning environment. They point out that the instructor needs to be an active listener and a coach. So that he can encourage the students to take responsibility of their own learning. This can be done effectively when the instructor gives continuous and prompt feedback to the students. (Chickering \& Gamson 1987)

\subsubsection{Handling drawbacks: Student and instructor rapport}

Confucius believed in affection and empathy towards students (Huanyin, Y., 1999). Chickering \& Gamson (1987) adviced instructors to "encourage contact between student and faculty". Tiberius \& Billson (Tiberius \& Billson, 1991 as cited by Fleming, 2003) emphasized on need of a trust based, open and cooperative relationship between an instructor and his students which is guided, not by control, but by mutual agreement. 
Active learning demands involvement. Involvement demands interaction. Fruitful interaction demands rapport. But that does not mean that an instructor has to indulge in students' appeasement. He has to rather strive for a growth oriented relationship with sincerity and honesty.

\subsection{Co-operative active learning}

Active learning may be implemented through different routes. One of the popular routes is cooperative active learning. Students' involvement amongst themselves is crucial for successful active learning environment. As Chickering \& Gamson (1987) stated, “learning isn't solo race rather it's a team effort which depends on collaboration and cooperation amongst students." In cooperative learning a class is divided into smaller groups to enhance understanding and learning of students through positive interdependence, individual accountability, continuous interaction, teamwork, to accomplish orderly thinking, problem solving, critical analysis and clear expression (Johnson et al. 1998).

Imagine six stand alone desktop computers and now compare it with a group of six networked computers. Which would give higher volume of fast information sharing and processing? Off course the networked group. Cooperative learning aims at developing a network of human brains to achieve higher levels of learning, and to prevent this network from crashing the size of the teams is kept smaller. Student attendance is essential in a cooperative learning environment as absence of one or few team member(s) might disturb the task accomplishment and create a negative impact on the team spirit. (McManus, 1996). Finlay and Faulkner (2005) conducted a project in which self help reading groups of 3-5 students were formed. Each student had to read a different topic each week and then had to write one page synopsis which was later discussed with the group. After the reading students asked questions among themselves. $73 \%$ of the students expressed positive perception of the method. Boud et al. (1999) refer to a term "peer learning" in which students learn in a group without intervention of an instructor.

Cooperative learning aims at self help in pursuit of knowledge. It may partially involve the instructor or it may be practiced without instructor's intervention. One logical adaptation would be to initiate cooperative learning with higher degree of instructor's involvement and intervention and to gradually reduce the involvement after judging the degree of self sufficiency of the group. Cooperative learning may promote social loafing. Latane et al. (1979) in their research found that individuals tend to reduce effort when performing in a group. This is called social loafing. Maniar (2002) researched team work in business and sports and found that individual input reduces with the increase in size of a team. To prevent social loafing he suggests to evaluate each individual on his/her contribution, give smaller awards along the way instead of rewarding the group at the end of the task. 


\subsection{Assignment based active learning}

Since 1988, University of Hawai at Manoa has been running "writing intensive" classes which aims at "learning through writing". (UHM 2006) An internal study has found that students have positive perception of the program and writing intensive assignments enhance learning amongst the students, but they need to be taught how to write to learn. The strategy used by the university is to guide students to improve their analytical skills through synthesis of the journal articles, improve their reading skills through writing summaries, learn data collection techniques, to improve their analytical skills by examining research articles and then to present their own views through writing intensive assignments. Plagiarism may be cited as a big drawback of writing intensive assignments but a software like 'Turnitin' (www.turnitin.com) helps to keep a check on students indulging in plagiarism.

\subsection{Problem based active learning}

Problem based learning is a self directed effort of a student towards understanding the solution of a problem. In this process the student identifies what he knows and what he needs to know to solve the problem. (Barrows and Tamblyn 1980) Instead of feeding the students with readymade content through lectures and discussions, problem based learning begins with a challenge of presenting a real life problem through case studies, research papers, assignment etc to the students, the answer to which they have to find on their own, individually and/or collectively. This method drastically changes the role of the students as well as the instructor.

The usual practice of teaching is to explain the concept to the students and then follow with questions. Problem based learning (PBL) is exactly opposite as in PBL the beginning is with a problem and in due course of time students acquire knowledge and skills to solve the problem. A teacher is no more a provider of quick and easy answers rather he becomes a facilitator in search of relevant information. The biggest challenge for successful implementation of PBL is the willingness and ability of the instructor to create a learning environment which is not teacher centered and in which the student actively guides his own learning, individually or in a group. (Barrows \& Tamblyn, 1980).

Second most important challenge while implementing PBL is the selection of a problem. Stinson \& Milter, (1996) suggest the selected problem should reflect real life circumstances and be contemporary to facilitate the process of learning and doing. They further suggest the problem to be ill-structured, as real life problems are rarely structured. An ill-structured problem would enable the student to comprehend ill defined situations. Duch (1996) insists that an effective problem must engage and motivate students, should be connected to previously learned knowledge, be open ended and not limited to one correct answer, must encourage higher level of learning by asking for solutions based on facts and logic. Duch (1996) further clarifies that instead 
of dividing the problem into smaller units to be individually solved by a student, an effective problem should encourage total involvement of a students group and prevent "divide and conquer" of the assignment. We may conclude that PBL attempts to bridge the gap between education and research.

\section{Multiple intelligence and multi-sense oriented learning.}

Gardner's (1993) concept of multiple intelligence identified that each individual has following eight facets of intelligence. Logical-mathematical intelligence makes a learner quick with numbers, strong in reasoning and scientific thinking. Verbal-linguistic makes a learner comfortable with languages and communication including verbal and written assignments etc. Musical-rhythmic intelligence relates to recognition and use of sounds and audio presentations. Naturalist intelligence relates to ability to work with nature, field trips, real life situations. Visualspatial relates to sense of sight and ability to make mental images and concept maps. Interrelational relates to inter personal skills such as communication and team work. Intra relational is associated with understanding of self. Bodily-kinesthetic is associated with body movements.

Visual based instructions using audio visual models, films, 3D graphs enhance the productivity of active learning environment (Cashin,1985; Bonwell \& Eison 1991). VARK (Visual, Aural, Read/Write, Kinesthetic) learning strategy attempts to create an active learning environment. In visual learning an instructor uses gestures and picturesque language, pictures, videos, posters, slides, colour flow-charts, colour graphs and diagrams, underlining and different colour highlighters etc.

In aural learning classroom discussions between learner and instructor and amongst learner play an important role. Outside classroom strategy involves spending time in a quiet place and recalling the ideas and speaking out the answers aloud or inside head to register the content in mind.

Read/write learning strategy works well when the content involves lots of definitions, glossaries, manuals, dictionaries. This strategy requires the students to undertake multiple writing and reading sessions. To reinforce learning frequent multiple choice tests are suggested.

In kinesthetic learning strategy field tours and trips, lectures with real life examples, laboratory sessions, learning from trial and error etc is given emphasis. Use of case studies and applications to help with principles and abstract concepts is suggested. (Complete information on VARK adapted from www.vark-learn.com).

A comprehensive active learning environment which can successfully engage the learners with consistency will need to address the issues of multiple intelligence and multiple human senses. A multi dimensional communication will strengthen the learning environment. Multiple intelligence 
identifies different facets of human intelligence, and a successful active learning environment needs to implement variety of tools to address these facets.

\section{Conclusion}

Active learning is more than a technique or a tool. Active learning is a way of life. There are three major components of an active learning environment and they are students, instructors and institute/management. Active learning environment demands behavior modification on the part of students, instructors and institute/management. The speed and intensity of implementing a step by step comprehensive active learning environment in higher education has to be determined by the desire, ability and willingness of the students, instructors and institute/management.

Instead of developing and implementing a learning environment which is decided by the management/faculty/consultant, the need identification for an activity based environment in the mindset of the students has to be given importance. There is a need of a paradigm shift from the usual approach of 'how I like to teach' to 'how the learner wants to learn and how the learner will learn better'.

Apart from the methods already discussed there are multiple tools to choose from for implementing active learning environment, such as,

- Group brainstorming

- Think-pair-share (A tool in which students are divided into groups of two and they discuss their understanding of the topic after a short lecture)

- One minute papers on the muddiest point, difficult topic, easiest definition etc.

- Concept maps (A tool which abets in comprehending the logical relationships amongst a number of ideas within a topic of discussion by creating a visual map of the connections.)

- Students role play, simulations.

- Short writing assignments/ summaries.

- Classroom debates and discussions.

One can pick and choose any combination of the methods and tools discussed in this research paper but the selection of a combination has to be guided by the habits, preferences, willingness, behaviour modification, knowledge base and learning style of the students and also the instructors.

Following may be considered as prerequisites for a successful active learning environment:

1. Clarity, creativity and likeability of the tools and techniques used

2. Degree (positive) of behaviour modification (engagement and involvement) of the students induced by the tools used.

3. Synergy of active learning environment with the present and required knowledge base of the instructor and learners. 
4. Synergy of active learning with course, syllabus and time schedule.

5. Availability of relevant case studies, problems, assignments, tests, related infrastructure.

6. Complete involvement of all the stakeholders: faculty, support staff, institute's management, students (individually \& jointly), and parents.

7. Examination performance enhancement by the tools and techniques used.

8. Within and outside classroom as well as within and outside college, learning continuity.

To conclude, active learning would start with an instructor who is an active learner and active instructor himself and who can upgrade his knowledge and skills in the time of need. He has to then identify the needs of the students with reference to changes expected in learning environment. He then has to balance the students needs with what he thinks is best for the learning environment. This would lead to the preliminary preparations in collaboration with the learners and would be followed by gradual, step by step implementation of the new methods and tools.

Continuous feedback from the students and supervision by the instructor might be essential at an early stage. Regular evaluation of the learning environment is essential through class tests, vivavoce, evaluation of assignments (by instructor or by students themselves), students' feedback (informal classroom feedback and/or formal questionnaire based feedback), peer feedback (by instructor's colleagues).

\section{References}

Astin, A.W. (1984). Student Involvement: A developmental theory for higher education. Journal of College Student Personnel, 25, pp. 297-308.

Barrows, H. S., \& Tamblyn, R. M. (1980). Problem-based Learning: An Approach to Medical Education. New York: Springer

Berk, R.A. (2003). Professors are from Mars, Students are from Snickers: How to write and deliver humor in the classroom and in professional presentations. Sterling, V.A.:Stylus Publishing

Bligh, D.A. (1972) Whats the use of lectures? Harmondsworth, Middlesex, England, Penguin Books.

Bonwell, C. \& J. Eison (1991) "Active learning: Creating Excitement in the Classroom", ASHEERIC Higher Education Report No. 1, Washington D.C., George Washington University School of Education and Human Development.

Boud, D., Cohen, R. \& Sampson, J. (1999) 'Peer Learning and Assessment', Assessment in Higher Education, 24, pp. 413-26

Cashin, W.E. (1985), Improving Lectures, Idea Paper No 14, Manhattan, KS: Centre for Faculty Evaluation and Development, Kansas State University.

Chickering, A.W. and Gamson, Z.F. (1987), Seven Principles for Good Practice, AAHE Bulletin, 39 (7), pp. 3-7.

Chilcoat, G. W. (1989). Instructional behaviors for clearer presentations in the classroom. Instructional Science, 18 , pp. 289-314. Abstract of the research findings downloaded on $10^{\text {th }}$ June 2006, from http://www.active-learning-site.com/sum1.htm

Dale, E. (1969), Audio-Visual Methods in Teaching ( $3^{\text {rd }}$ Edition), Holt, Rinehart, and Winston.

Duch, B. (1996) Problems: A Key Factor in PBL, Center for Teaching Effectiveness. Downloaded on $15^{\text {th }}$ June, 2006, from, http://www.udel.edu/pbl/cte/spr96-phys.html

Fedler, R.M., Brent, R. (1996) Navigating the bumpy road to student-centered instruction, College Teaching, 44, pp. 43-47 
Finlay, S.J., Faulkner, G. (2005) Tete a tete: Reading groups and peer learning, Active Learning in Higher Education, 6(1), pp. 32-35

Fleming, N. (2003), Establishing Rapport: Personal Interaction and learning, Idea Paper No. 39, Manhattan, KS: Centre for Faculty Evaluation and Development, Kansas State University.

Forrest, S.,(2004) Learning and Teaching: The Reciprocal Link, The Journal of Continuing Education in Nursing, 35(2), pp. 74-79

Gardner, Howard. Multiple Intelligences: The Theory in Practice. New York: Basic, 1993.

Huxman, M. (2005) Learning in lectures: Do 'interactive windows' help?, Active learning in higher education, 6(1), pp. 17-31

Huanyin, Y., (1993), Confucius: K'ung Tzu (551-479 BC), Prospects: the quarterly review of comparative education (Paris, UNESCO: International Bureau of Education), vol. XXIII, no. $1 / 2$, pp. 211-19.

Johnson, D.W., Johnson R.T., \& Smith, K., Active Learning: Cooperation in the College Classroom, Interaction Book Company, Edina, MN, 1991.

Lammers, W.J. \& Murphy, J.J. (2002)'A Profile of Teaching Techniques Used in the University Classroom', Active Learning in Higher Education, 3, pp. 54-67

Latane, B., Williams, K., \& Harkins, S., (1979) Many Hands Make Light The Work: The Causes and Consequences of Social Loafing, JPSP, 37(6), pp. 822-832.

Maniar, S. (2004) , Improving Group Performance in Business \& Sport: Part I - Social Loafing, Optimal Performance Newsletter, 2(2)

McManus, D. A. (1996), Changing a Course from Lecture Format to Cooperative learning, Paideia: Undergraduate Education at the University of Washington, 4(1), pp. 12-16

Meyers, C., \& Jones, T.B. (1993). Promoting Active learning: Strategies for the college classroom. San Francisco: Jossey-Bass.

Murray, R. \& Brightman, J.R. (1996) 'Interactive Teaching', European Journal of Engineering Education, 21, pp. 295-308

Ruhl, K. L., Hughes, C. A., \& Schloss, P. J. (1987). Using the pause procedure to enhance lecture recall. Teacher Education and Special Education, 10, pp. 14-18. Abstract of the research paper downloaded on $10^{\text {th }}$ June,2006, from http://www.active-learning-site.com/sum1.htm

Russell. I.J., Hendricson, W.D., \& Herbert, R.J. (1984). Effects of lecture information density on medical student achievement. Journal of Medical Education, 59, pp. 881-889. Abstract of the paper downloaded on $10^{\text {th }}$ June,2006, from http://www.active-learning-site.com/sum1.htm

Sander, P., Stevenson, K., King, M., \& Coates, D. (2000) 'University Students: Expectations of Teaching', Studies in Higher Education, 25, pp. 309-23

Seeler, D. C., Turnwald G. H., Bull, K. S. (1994) From Teaching to Learning: Part III. Lectures and Approaches to Active Learning, Journal of Veterinary Medical Education, Volume 21, Number 1. (Spring). Downloaded on $15^{\text {th }}$ June, 2006, from http://scholar.lib.vt.edu/ejournals/JVME/V21-1/Seeler1.html

Stinson, J.E. \& Milter, R.G. (1996) Problem-Based Learning in Business Education:Curriculum Design and Implementation Issues, New Directions in Teaching and Learning in Higher Education, Jossey-Bass, 1996. Downloaded on $15^{\text {th }}$ June, 2006, from http://www.ouwb.ohiou.edu/stinson/PBL.html

Tiberius, R.G. and Billson, J.M.(1991). The social context of teaching and learning. In R.J. Menges and M.Svinicki (Eds.), College Teaching: From theory to practice. San Fancisco: Jossey-Bass.

Wilke, R. Russell (2003), The Effect of Active Learning on Student Characteristics in a Human Physiology Course for Non-majors, Advances in Physiology Education, 27, pp. 207-223

UHM (2006) Writing Matters, Manoa Writing Program, The University of Hawai At Manoa, Downloaded on $25^{\text {th }}$ June, 2006, from http://www.mwp.hawaii.edu/resources/wm1.htm

Cite as: Naithani, P. (2008). Reference framework for active learning in higher education. In Al-

Hawaj, Elali and Twizell (Eds.) Higher Education in the Twenty-First Century: Issues and

Challenges, 113-120, Taylor \& Francis Group, London. 